\title{
Retrospective Clinical Study on Epistaxis
}

\author{
Md Sharif Alam ${ }^{\circledR 1}$, R P Thakur ${ }^{\circledR 2}$ \\ ${ }^{1}$ Senior Resident, Department of ENT, Anugarah Narayan Magadh Medical College \& Hospital, Gaya, Bihar, India, ${ }^{2}$ Associate Professor, Department of ENT, Anugarah \\ Narayan Magadh Medical College \& Hospital, Gaya, Bihar, India.
}

\section{Abstract}

Background: Epistaxis is bleeding through nose. It is most common emergency situation in ENT that is disastrous to the patient and troublesome to treat for doctors. It is seen that $60 \%$ population experiences epistaxis in their life time and only $6 \%$ went to take consultation. The study aims to evaluate incidence, etiology, provoking factors and cost effective management. Subjects and Methods: A 3 years retrospective study between September 2015 to August 2018 carried out in Anugarah Narayan Magadh Medical College \& Hospital, Gaya on 98 admitted epistaxis patients. Results: Total 11,667 patients came in ENT department among them 2,723 patients with nasal complain. Incidence was $0.84 \%$ among all cases and 3.6\% among nasal problems. No obvious cause seen in 34 cases $(34.23 \%)$ then cardiovascular cause in 32 cases (32.65\%) then infection in $19.32 \%$ and lastly by trauma in 5.68\%. Maximum patients in 40-50 years age group 36\% and minimum in $70-80$ years $1 \%$. Most patients belong to urban76 cases (77.27\%) and middle age 36 cases (36.36\%). Males are more prone 57 cases (57.95\%) with ratio 1.39:1. Mostly in January-March months 45 cases (46.59\%). Most patients came with unilateral epistaxis 86 cases $(87.5 \%)$. About 26cases (26.14\%)came with single episode whom urgent treatment required. Well managed with Nonsurgical method to 85 patients $(86.73 \%)$ by anterior nasal packing (ANP) in 43 cases (43.87\%) and chemical cauterization to 19 cases(19.30\%) while surgical treatment given to 13 patients (13.26\%).Some required electrocauterization 16 cases (16.32\%) with bipolar. Mean hospital stay length 3.2 days. Blood transfusion required in 7 cases ( $7.14 \%$ ). Conclusion: Cost effectively anterior nasal packing is best conservative indirect method and electrocauterization is very effective direct method.

Keywords: Epistaxis, Anterior nasal packing, Bipolar Cauterization

Corresponding Author: Md Sharif Alam, Senior Resident, Department of ENT, Anugarah Narayan Magadh Medical College \& Hospital, Gaya, Bihar, India.

E-mail: sharifdralam@gmail.com

Received: 11 February 2020

Revised: 22 March 2020

Accepted: 29 March 2020

Published: 26 May 2020

\section{Introduction}

Bleeding through nose and nasal cavity called epistaxis. It issymptom and present as most common complain in the emergency. It is very disastrous situation for the attendant \& sometime very difficult to manage for the doctors too. It has bimodal age distribution mostly seen is $<10$ years and $>40$ years age. Males are more prone for this symptom. It is seen that $60 \%$ people experiences their life time to epistaxis and $6 \%$ population only went to take consultation. ${ }^{[1]}$

There are various etiological \& provoking factors as local, general and idiopathic. Among local most commonly seen to the trauma and in general most commonly seen to the hypertension. Among over all idiopathic is superior to both of them. Various modalities of treatment available among them traditional non surgical method is nasal packing very effective \& bipolar cautry under local anesthesia for bleeding polyps, whoever transnasal sphenopalatine artery ligation is much effective. ${ }^{[2]}$ Overall epistaxis to be very disastrous for patients and troublesome to treat for physician.

There are various classifications of epistaxis. ${ }^{[3]}$ Among those most structured and clinical classification is :

Primary — No proven causal factor (idiopathic)

Secondary - Proven causal factors.

Childhood $-<16$ yrs.

Adult $->16$ yrs.

Anterior - Bleeding point anterior to pyriform aperture.

Posterior - Bleeding point posterior to pyriform aperture.

It is also grouped as recurrent \& one time. It is seen that it is more common in the Autumn and Winter months. There is also circadian fluctuation epistaxis more in the morning and late evening time.

The study aims to evaluate the incidence, etiological, provoking factors and cost effective management. 


\section{Subjects and Methods}

This is a retrospective study of 3 years between Sep-2015 to August-2018 in Department of ENT in Anugarah Narayan Magadh Medical College, Gaya. Here we have collected data from the OPD, emergency rooms and the indoor ward for the epistaxis management.

During this period 98 patients after taking consent admitted and we have evaluated those for their demography, social factors, associated medical conditions, treatment received \& etiological factors.

Here we also discuss the month of admission, length of hospital stay, treatment modality non surgical / surgical and the need of blood transfusion.

Before going to treatment we evaluate patients $\mathrm{CBC}, \mathrm{BT}$, $\mathrm{CT}, \mathrm{PT} / \mathrm{INR} \& \mathrm{APTT} \&$ if required we go for the supportive investigations as BU, Sr. creatinine, BUN, Sr. bilirubin, Sr. SGOT, Sr. SGPT, RBS \& blood grouping.

\section{Results}

This study comprises 98 patients admitted for the management of epistaxis in the ENT \& HNS department of Anugarah Narayan Magadh Medical College \& Hospital, Gaya, Bihar.

\section{Incidence}

Around 11,667 patients had attended to the ENT department of ANMMCH, GAYA and around 2,723 patients was complaining for the nose problems. Among them 98 patients got management for the epistaxis. Hence incidence of epistaxis is $0.84 \%$ in all cases and $3.60 \%$ among the nasal problems.

\section{Demography}

\begin{tabular}{|lll}
\hline Table 1: Age Group & & \\
\hline Age group & No.of cases & Percentage (\%) \\
$0-10$ & 5 & 4.55 \\
$11-20$ & 12 & 12.50 \\
\hline $21-30$ & 10 & 10.23 \\
$31-40$ & 9 & 9.09 \\
$41-50$ & 36 & 36.36 \\
\hline $51-60$ & 18 & 18.36 \\
\hline $61-70$ & 7 & 6.82 \\
\hline $71-80$ & 1 & 1.14 \\
\hline Total & 98 & 100.00 \\
\hline
\end{tabular}

Patient's age vary from the $6 \mathrm{y}(\mathrm{y}=\mathrm{years})$ to $78 \mathrm{y}$ and most of the pts.(patients) were above 40y. Maximum pts. seen in the age group (40-50y) and minimum in (70-80y) age group $36(36.36 \%)$ and $1(1.4 \%)$ respectively. Mean age was $(47.87 y)$ out of 98 pts. mostly were Hindu 77(78.41\%); 12(12.54\%) Muslims and 9(9.09\%) were Christians. Most pts. belong to the urban $76(77.27 \%$ ) region and mostly were middle age 36 cases $(36.36 \%)$.

\section{Sex-Ratio}

Males are mostly affected $57(57.95 \%)$ compared to the female $41(42.05 \%)$.Ratio is $(1.39: 1.0)$

\section{Seasonal variation}

Most pt. had come between January to March months 45(46.59\%), whoever epistaxis pts. mostly seen in Autumn \& Winter months.

\section{Symptomatology}

Most pt. had come with complain of unilateral epistaxis $86(87.50 \%)$ and bilateral $12(12.50 \%)$. Majority of pts. complain for recurrent nonsevere but about 26(26.14\%) pts. had come with the single episode with severe bleeding whom urgent treatment required.

\section{Etiology}

Exact etiology was not known in most pt. 34 cases $(34.23 \%)$ that means idiopathic, next most common was Cardiovascular(hypertension etc.) 32 cases $(32.65 \%)$ then infection $(19.32 \%)$, trauma $(5.68 \%)$ etc.

\begin{tabular}{lll}
\hline Table 2: Symptoms & & \\
\hline Symptoms & No. of Patients & Percentage (\%) \\
Epistaxis & 98 & 100.00 \\
Mass in nose & 22 & 23.86 \\
Nasal blockage & 45 & 46.53 \\
Nasal discharge & 35 & 36.36 \\
Pain over the nose & 20 & 20.45 \\
Trauma & 6 & 6.12 \\
\hline $\begin{array}{l}\text { Headache } \\
\text { Swelling over the }\end{array}$ & 39 & 40.00 \\
nose & & 7.95 \\
Breathlessness & 4 & \\
Fever & 2 & 4.58 \\
Palpitation & 1 & 2.27 \\
$\begin{array}{l}\text { Swelling } \\
\text { cheek }\end{array}$ & 1 & 1.14 \\
\hline \begin{tabular}{l} 
Proptosis \\
\hline
\end{tabular} & 1 & 1.14 \\
\hline
\end{tabular}

\section{Local examination}

On external examination nasal deformity found in the 9 cases $(9.09 \%)$ due to injury in 6 cases, 1 due to nasomaxillary carcinoma, one had congenital deformity and one had swelling. On anterior rhinoscopy, active bleeding seen in 14 cases $(14.77 \%)$ and in rest clot was seen. Then patients had 


\begin{tabular}{lll}
\hline Table 3: Causes & & \\
\hline Causes & No. Of cases & Percentage (\%) \\
\hline Idiopathic & 34 & 35.23 \\
\hline Trauma (Injury/Surgery) & 6 & 5.68 \\
\hline Infection & 19 & 19.32 \\
CVS (HPTN \& Arteriosclerosis) & 32 & 32.65 \\
\hline Bleeding diathesis(Liver disease) & 4 & 4.55 \\
Neoplastic & 1 & 1.14 \\
Uraemia & 2 & 2.27 \\
\hline
\end{tabular}

gone through diagnostic nasal endoscopy ${ }^{[4]}$ in which bleeding or oozing (after clot removal) from the septum seen in 55 $(56.82 \%)$ in which 40 cases $(40.91 \%)$ from anterior part and remaining 15 cases from posterior. It is also seen that in 25 cases $(26.14 \%)$ bleeding coming from lateral nasal wall among them 13 cases $(13.64 \%)$ from inferior turbinate and 12 cases $(12.50 \%)$ from the middle turbinate \& middle meatus. In 28 cases $(29.55 \%)$ bleeding was coming for the nasal floor in which 24 cases $(25.0 \%)$ was anterior and remaining $4(4.55 \%)$ was posterior.

\begin{tabular}{|c|c|c|}
\hline Side of bleeding & Cases & Percentage (\%) \\
\hline $\begin{array}{l}\text { 1. Septum Ant.- } \\
40(40.31 \%)\end{array}$ & 55 & 56.84 \\
\hline \multicolumn{3}{|l|}{ Post.-15(15.91\%) } \\
\hline $\begin{array}{l}\text { 2. Lateral wall } \\
\text { Inferior turbinate - } \\
13(13.04 \%)\end{array}$ & 25 & 26.14 \\
\hline \multicolumn{3}{|l|}{ Middle turbinate- 12} \\
\hline $\begin{array}{l}\text { 3. Floor Ant.- } \\
24(25 \%)\end{array}$ & 28 & 29.55 \\
\hline Post.-4(4.55\%) & & \\
\hline
\end{tabular}

Mass is also seen in the nasal cavity in 23 cases (23.86\%) and that was from the lateral wall in $19(19.32 \%)$ and in which 12 $(12.50 \%)$ from the middle meatus, $6(5.68 \%)$ from the inferior turbinate region and $1(1.14 \%)$ from middle turbinate, floor had 4 cases. Bleed on touch mass 22 cases $(22.73 \%)$ seen among them. DNS in 21 cases $(21.59 \%)$ and 4 cases had bony spur seen.

\section{Treatment}

There are various modalities of treatment described but we had done by classifying non surgical \& surgical method. First departmental protocol for the management of epistaxis is- Pt. Who come to the OPD or Emergency not have active bleeding or simply staining, we treat him on medications. Those pts. who come with active anterior nasal or posterior nasal bleeding or recurrent bleeding with oozing found on examination or clot removal may be treated after taking admission. First pt. go for thorough examination as by anterior rhinoscopy and diagnostic nasal endoscopy. If bleeder identified with slight oozing first go for local chemical cauterization and gelfoam placement. Material used for chemical cauterization are silver nitrate, trichloroacetic acid, phenol\& chromic acid. They applied to the desired place with bud soaked in those solution over red dots in unilaterally only, also for electrocautery with bipolar cases. In bilateral cases simply nasal paking is better. If bleeding controlled then discharged. If pt. bleed again then go for tight nasal packing on that side and loose on other. If bleeding not controlled after 48hours then may go for electrocautery with bipolar in unilateral cases after identifying bleeding point by nasal endoscopy and suction .Then nasal packing again done, in bilateral cases either anterior nasal packing or posterior nasal packing as per requirement should be done. Mostly bleeding stops at this stage if not controlled may go for correction of etiology eg. Septoplasty for bleeder not identigied behind spur or gross deviated septum, FESS, mass removal \& coagulation profile correction. If again bleeding not stops we can go for arterial ligation eg. TESPAL (Transnasal Endoscopic Sphenopalatine Artery Ligation), anterior ethmoidal artery ligation by incising medial canthus \&retracting orbital contets laterally \& maxillary artery in Pterygopalatine fossa by removing posterior wall of maxillary sinus. In non surgical method 85 patients (86.73\%) got $\mathrm{t} / \mathrm{t}$ in that $40(43.18 \%)$ cases had managed by ANP (Anterior Nasal Packing), 19 cases (19.31\%) require local chemical cauterization \& electrocauterizationt/t given to the 16 cases $(15.91 \%)$. While surgical treatment given to 13 cases(13.26\%) after proper anesthetization. Most cases recover after nonsurgical management. Very few left that had gone through surgical maneuvers. Hospital stay ranged from 1 to 5 days mean length of hospital stay is 3.2 days. Blood transfusion required in the 7 cases $(6.52 \%)$. No casualty had seen.

\section{Vascular Anatomy}

Nose is highly vascular structure in the body and the key area for epistaxis are:- 


\begin{tabular}{|c|c|c|}
\hline $\begin{array}{l}\text { Various treat- } \\
\text { ment }\end{array}$ & No. Of cases & Percentage (\%) \\
\hline Non surgical & 85 & 86.73 \\
\hline $\begin{array}{l}\text { Local chemical } \\
\text { cauterization }\end{array}$ & 19 & 19.31 \\
\hline Electrocauterizatio & 16 & 15.91 \\
\hline Anterior packing & 43 & 43.87 \\
\hline Posterior packing & 1 & 1.14 \\
\hline $\begin{array}{l}\text { Foley's catheter } \\
\text { in PNP }\end{array}$ & 6 & 6.82 \\
\hline Surgical & 13 & 13.26 \\
\hline Septal surgery & 4 & 4.55 \\
\hline Sinus surgery & 9 & 9.09 \\
\hline Arterial ligation & 0 & 0 \\
\hline
\end{tabular}

1. Little's area - kiesselbach's area-Anteroinferior part of septum

2. Retrocolumallar vein- vertical vein passes $2 \mathrm{~mm}$ behind the columella

3. Woodruff's plexus

4. Lateral wall\& high post septal region

It is not correct to say that if no any bleeding point seen in epistaxis regarded as post nasal bleed. But it is seen after endoscopy that it comes from high post. septal region. Septal and lateral branch of the sphenopalatine artery \& post. ethmoidal artery are trouble some bleeder artery in post. epistaxis. It is also seen that mostly post. epistaxis comes from woodruff's plexus- It is a venous plexus \& its sites are:

1. Post $1 / 3$ rd of nasal floor

2. Inferior meatus

3. Inferior turbinate posterior end

4. Middle meatus

5. Vertical mucosal strip anterior to both eustachian tube

6. Lateral \& superior part of mucosa above to the posterior choana adjacent to the sphenoid rostrum.

\section{Discussion}

Epistaxis is a frequent complain by the patients in ENT department. As we know epistaxis causing mortality in the ENT prominently after the Head Neck carcinoma. We also know the bimodal age distribution of the epistaxis patient. Here we found that $>40 \mathrm{y}$ age group was more affected probably due to general cause (cardiovascular) having mean age was $47.8 \mathrm{y}$. This study correlate well with the study of (Hicks \& Norris, 1989). Men (57.95\%) are affected more than female $(42.05 \%)$ by ratio $(1.39: 1)$ correlate well. Here, according to shaheen (Scott Brown 7thed Vol II) hypertension is a cardiovascular disease has no role in the initiation of this rather persistance. Hypertension causes muscle layer degeneration hence vessels cannot contract properly that leads to persistence of the epistaxis. He also found smoking \& alcohal is associated factors $26 \% \& 27 \%$ respectively. Overall major cause of epistaxis is still unknown. The other main cause of epistaxis is hypertension was a major etiological factor found by the Monjas et al. ${ }^{[5]}$

Each patient in study goes through proper history, drug intake history and thorough examination. If bleeding point localized anteriorly chemical cauterization done, if bleeding seems to be coming from the posteriorly then electrocautery could be tried in unilateral cases, if again bleeding vessel not identified go for the indirect method of management eg. Anterior nasal packing or posterior nasal packing as per requirement. Mostly managed at this stage but again bleeds after pack removal then first trried to localise bleeder or bleeding point and electrocauterized with bipolar \& repacked. After this, if pt. bleed again then may go forligation by localizing the bleeding part, ${ }^{[6,7]}$ reference will be middle turbinate for superior and inferior (ICA \& ECA); middle meatus for ant.\& posterior epistaxis further, if bleeder seems to be behind the septal spur go for septoplasty. By raising the flap and removing the septal spur bleeding can be controlled. Some pt. had gone through sinus surgery (FESS) as it is both diagnostic and therapeutic procedure. ${ }^{[8]}$ In elderly patient extra caution must be taken as heart has already compromized during anaesthesia and nasal packing (vasovagal attack) especially in post nasal pack (decrease in spo2). Every patient first assessed for how much blood loss occured. Care taken in elderly by giving blood cell suspension. Argon laser used for treatment of Hereditary Haemorrhagic Telangiectasia with septodermoplasy. ${ }^{[9]}$ In recurrent and intractable epistaxis in HHT some advocate for Bevacizumab (amonoclonal antibody) both topically and local infilteration. Tamoxifen has also suggested for use to allay need of blood transfusion.

Every patient after anterior rhinoscopy had gone through endoscopic examination to visualize the bleeding point. ${ }^{[4]}$ In case of Maurer's triad blilndness in one eye, Orbital fracture and profuse nasal bleeding can go for arterial ligation but with failure rate $10-14 \% .{ }^{[4,7,8,10-13]}$ Due to high collateral circulation distalmost artery should be addressed (eg. ESPAL or endoscopic sphenopalatine arterial ligation). We had no need for arterial ligation in this study. A part from high failure rate, posterior nasal packing is associated with considerable discomfort, mucosal trauma and morbidity due to hypoxia. ${ }^{[1]}$ It causes nasal necrosis especially alar cartilage instantly, about in 4 hours due to tight thread tie. ${ }^{[1,12]}$ But due to easiness used readily and thread put over small gauze pad.

In management of patient, divided in 2 category:

(i) Non Surgical / Conservative method. 
(ii) Surgical / Non conservative method.

First we had tried conservative indirect method in bilateral cases, if failed then had gone to surgical/Non conservative method eg. Septoplaty, FESS, TESPAL etc. ${ }^{[14,15]}$ In unilateral cases first we had tried to locate bleeder then gone for direct method and loose pack, if bleeder not localised properly then could go for indirect/ nasal packing. In case of severe epistaxis there must be keeping three points for choosing the appropriate method.

\section{(i) Efficiency \\ (ii) Complications}

\section{Cost benefit}

As in indirect conservative method ant. nasal packing is easily administered \& removed with efficiency of $45 \%$. It has failure rate $(29.55 \%)$ which is within $26-52 \%$. Failed case had gone to eletrocauterization under local anaesthesia and packing or Foley's catheterization for post nasal pack. In one case cotton gauze pack given as PNP (Posterior nasal pack).PNP usually along with anterior nasal packing. There are manycomplications of this procedure.- Hypoxia, cardiac arrythmia, myocardial ischaemia, CO2 poisoning\& $\mathrm{Gm}$-ve bacteraemia. Very few minor complications are Eustachian tube dysfunciton, sinusitis, septal perforation \& facial edema. In our study facial edeme \& clouding of sinuses seen, overall bipolar cautery after endoscopy coming out as best tool to manage the bleeding. ${ }^{[13]}$ Because in Direct method its result is better than chemical cauterization. In our study no failed case seen with bipolar eletrocautery. ANP (Anterior Nasal Packing) is still common method employed to control epistaxis as it is very effective and easily available at every emergency room. It is cost effective because gauze, liquid paraffin \& antiseptic cream easily available. Only application is painful but easy to administer for doctors, this can be avoided by prior application of Lignocain jelly. Material for cauterization and surgeries are very costly. In our study 85 cases $(86.73 \%)$ managed conservatively by Non surgical method correlate well with Philip et. al (83\%) and Arshad et. Al (81.66\%). ${ }^{[14,15]}$ For surgical/Non conservative management only 13 cases $(13.26 \%)$ remain, which is near to Villwock et al (8.1\%);Out of 57,039 pts. in different hospital surgical intervention required only in $8.1 \%{ }^{[16]}$ In $6.92 \%$ of cases blood transfusion required. We found mean hospital stay 3.2 days which is comparable to other study, \& no mortality. ${ }^{[17-20]}$

\section{Conclusion}

There is great chances of complications facing during severe epistaxis management. In our study there is still unknown the exact main cause then cardiovascular and infections are causative agents.
Main non surgical method of treatment has found simply ANP (Anterior nasal packing) because it is cost effective and easy to administer then local cauterization. Order of Non surgical management was local cauterization or anterior nasal packing or posterior nasal packing with Foley's catheterization or with gauze. Bipolar cauterization under LA with loose nasal pack for anterior nasal bleed and bipolar cautery loose pack with catheterization (Foley's) for profuse posterior nasal bleed was very effective in unilateral and Direct method.

We have very superficial knowledge about spontaneous epistaxis so there must be such investigation that clear our way of epistaxis management.

\section{References}

1. Beck R, Sorge M, Schneider A, Dietz A. Current Approaches to Epistaxis Treatment in Primary and Secondary Care. Dtsch Arztebl Int. 2018;115(1-2):12-22. doi:10.3238/arztebl.2018.0012.

2. İsmi O, Vayisoğlu Y, Özcan C, Görür K, Ünal M. Endoscopic Sphenopalatine Artery Ligation in Posterior Epistaxis: Retrospective Analysis of 30 Patients. Turk Arch Otorhinolaryngol. 2016;54(2):47-52. doi:10.5152/tao.2016.1713.

3. Manickam A, Ghosh D, Saha J, Basu SK. An Aetiopathological Study on Epistaxis in Adults and its Management. Bengal J Otolaryngol Head Neck Surg. 2015;23(1):12-17.

4. Safaya A, Venkatchalam VP, Choudhary N. Nasal Endoscopy evaluation in epistaxis. Ind J Otolaryngol Head Neck Surg. 2000;52:133-139.

5. Monjas-Cánovas I, Hernández-García I, Mauri-Barberá J, Sanz-Romero B, Gras-Albert JR. Epidemiology of epistaxis admitted to a tertiary hospital. Acta Otorrinolaringologica. 2010;61(1):41-47. Available from: https://dx.doi.org/10.1016/ s2173-5735(10)70007-7. doi:10.1016/s2173-5735(10)700077.

6. Chattopadhyay PK. Evaluation of Symptoms in Cases of Otitis Media - A Clinical Study. Asian J Med Res. 2019;8(2):1-03. doi:10.21276/ajmr.2019.8.2.EN1.

7. Wang L, Vogel DH. Posterior Epistaxis: Comparison of Treatment. Otolaryngol Head Neck Surg. 1981;89(6):10011006. Available from: https://dx.doi.org/10.1177/ 019459988108900624. doi:10.1177/019459988108900624.

8. Kennedy DW. Functional Endoscopic Sinus Surgery: Technique. Archives Otolaryngol Head Neck Surg. 1985;111(10):643-649. Available from: https: //dx.doi.org/10.1001/archotol.1985.00800120037003. doi:10.1001/archotol.1985.00800120037003.

9. Dixon JA, Parlein JL. Laser Photocoagulation in HHT. Otolaryngol Head Neck Surg. 1981;89:204-204.

10. Rosnagle RS, Yanagisawa E, Smith HW. SPECIFIC VESSEL LIGATION FOR EPISTAXIS: SURVEY OF 60 CASES. Laryngoscope. 1973;83(4):517-526. Available from: https://dx.doi.org/10.1288/00005537-19730400000008. doi:10.1288/00005537-197304000-00008.

11. Sehaitkin B, Strauss M, Houck JR, Hershey PA, Epistaxis. Medical versus surgical therapy; A comparison of efficacy, 
complications, and economic considerations. Laryngoscope. 1987;97:1392-1398.

12. Raushan EA, Kumar A. Traumatic Optic Neuropath: Is this the Ideal Management Protocol? Asian J Med Res. 2019;8(4):1-3. doi:10.21276/ajmr.2019.8.4.EN1.

13. Pollice P, Yoder M. Epistaxis: A retrospective review of hospitalized patients. Otolaryngol Head Neck Surg. 1997;117(1):4953. Available from: https://dx.doi.org/10.1016/s0194-5998(97) 70205-5. doi:10.1016/s0194-5998(97)70205-5.

14. Philip AP, Milton GY. Epistaxis: A retrospective review of hospitalized patient. AJO Head Neck Surg. 1997;117(1):4953.

15. Arshad M, Ahmad Z, Liaqat A. Epistaxis: An experience with over 100 cases. Rawal Med J. 2007;32(2):142-147.

16. Villwock J, Jones K. Recent trends in epistaxis management in the United States. JAMA Otolaryngol Head Neck Surg. 2008;(12):1279-84.

17. Kuhn A, Hallberg OE. Epistaxis :An experience with over 100 cases. Arch Otolaryngol. 1955;62:130-130.

18. Maurer JJ, Miles M. Epidemiology of epistaxis admitted to tertiary hospital. J Neurosurg. 1961;18:837-837.
19. Monux A, Tomás M, Kaiser C, Gavilán J. Conservative management of epistaxis. $\mathrm{J}$ Laryngol Otol. 1990;104(11):868-870. Available from: https://dx.doi.org/10. 1017/s0022215100114203. doi:10.1017/s0022215100114203.

20. Juselius H. Epistaxis a clinical study of 1,724 patients. J Laryngol Otol. 1974;88(4):317-327. Available from: https://dx.doi.org/10.1017/s0022215100078749. doi:10.1017/s0022215100078749.

Copyright: (C) the author(s), 2020. It is an open-access article distributed under the terms of the Creative Commons Attribution License (CC BY 4.0), which permits authors to retain ownership of the copyright for their content, and allow anyone to download, reuse, reprint, modify, distribute and/or copy the content as long as the original authors and source are cited.

How to cite this article: Alam MS, Thakur RP. Retrospective Clinical Study on Epistaxis. Acad. J Surg. 2020;3(1):31-36.

DOI: dx.doi.org/10.47008/ajs/2020.3.1.7

Source of Support: Nil, Conflict of Interest: None declared. 